\title{
A implementação da disciplina de Libras no contexto dos cursos de licenciatura ${ }^{1}$
}

\author{
Otávio Santos Costa ${ }^{2}$ \\ Cristina Broglia Feitosa de Lacerda ${ }^{3}$
}

\section{Introdução}

Com a promulgação da Lei n. 10.436 de 24 de abril de 2002 (BRASIL, 2002) - que reconhece a Língua Brasileira de Sinais (Libras) como meio legal de comunicação dos surdos, determina que sejam garantidas formas para sua institucionalização e difusão, bem como a implementação da Libras como disciplina curricular obrigatória nos cursos de formação de professores e Fonoaudiologia e sua posterior regulamentação através do Decreto n. 5.626 de 22 de dezembro de 2005 (BRASIL, 2005), estudos vêm sendo desenvolvidos em diversas partes do Brasil acerca da implementação da disciplina de Libras no ensino superior, com destaque para sua implementaçáo nos cursos de licenciaturas.

1 Pesquisa vinculada ao projeto em rede "Acessibilidade no Ensino Superior", da Faculdade de Filosofia e Ciências da Universidade Estadual Paulista (FFC-Unesp), Marília/ SP, financiada pelo Programa Observatório da Educação (Obeduc), da Coordenação de Aperfeiçoamento de Pessoal de Nível Superior (Capes) - Edital n. 49/2012.

2 UFSCar - Universidade Federal de São Carlos. Programa de Pós-Graduação em Educação Especial. São Carlos - São Paulo - Brasil. Mestrando. Bolsista Obeduc/Capes. Brasil. otaviocosta@gmail.com

3 UFSCar - Universidade Federal de São Carlos. Programa de Pós-Graduação em Educação Especial. São Carlos - São Paulo - Brasil. Pesquisadora do projeto em rede "Acessibilidade no Ensino Superior" (Obeduc/Capes). Brasil. clacerda@ufscar.br 
No campo da formação de professores, o Decreto n. 5.626/2005, em seu artigo $9^{\circ}$, do capítulo III, dispóe sobre prazos e percentuais mínimos para a implementação progressiva da disciplina de Libras, determinando o prazo final de dez anos, a partir de sua promulgação, para que cem por cento dos cursos de licenciatura e Fonoaudiologia das Instituiçóes de Ensino Superior (IES) ofereçam a disciplina, priorizando sua implementação nos cursos de Educação Especial, Fonoaudiologia, Pedagogia e Letras (BRASIL, 2005).

Também é disposto no Decreto o prazo, a partir de um ano de sua publicação, para a implementação da Libras como disciplina curricular optativa para os demais cursos de educação superior e na educação profissional (BRASIL, 2005).

O Decreto n. 5.626/2005 defende a educação bilíngue, definindo-a e determinando os espaços onde deve ser implantada: "São denominadas escolas ou classes de educação bilíngue aquelas em que a Libras e a modalidade escrita da Língua Portuguesa sejam línguas de instrução utilizadas no desenvolvimento de todo o processo educativo" (BRASIL, 2005).

Para os anos finais do ensino fundamental, ensino médio e educação profissional, campo de atuação dos egressos dos cursos de licenciaturas, segundo o Decreto n. 5.626/2005, a educação bilíngue pode ser desenvolvida com atuação de "docentes das diferentes áreas do conhecimento, cientes da singularidade linguística dos alunos surdos, bem como com a presença de tradutores e intérpretes de Libras-Língua Portuguesa" (BRASIL, 2005, art. 22, inciso II).

Nesse contexto, há um movimento para o reconhecimento da importância da Libras no processo de educação dos surdos e busca-se levar os futuros professores (alunos de licenciaturas) a conhecer em alguma medida essa língua, procurando favorecer o atendimento educacional que prestarão aos alunos surdos. A implementação da disciplina de Libras nos cursos de licenciaturas pode fortalecer a inclusão escolar desses alunos. No entanto, faz-se mister considerarmos alguns aspectos sobre essa inclusão. Apesar de a comunidade surda ser contemplada com a política de educação bilíngue, os pressupostos da inclusão escolar defendida de forma geral pelo Ministério da Educaçáo (MEC) conflitam com os pressupostos de educação bilíngue defendidos no Decreto n. 5.626/2005.

Ao analisar os diferentes sentidos atribuídos à educação bilíngue e à inclusão, destacamos o que está presente em dois documentos bastante centrais nesse debate: a Política Nacional de Educação Especial na Perspectiva da Educação Inclusiva, e o Decreto n. 5.626/2005. Para tanto, nos apoiamos em Lodi (2013), que observa que apesar da elaboração da Política por meio de um discurso que busca uma aproximação com os princípios da educação bilíngue para surdos constitutivos do Decreto, há um nítido distanciamento entre suas proposituras, principalmente pelo papel que a Libras ocupa nos referidos documentos. Segundo a autora: 
O Decreto compreende educação bilíngue para surdos como uma questão social que envolve a Língua Brasileira de Sinais (Libras) e a língua portuguesa, em uma relação intrínseca com os aspectos culturais determinantes e determinados por cada língua; a Politica, por sua vez, reduz educação bilíngue à presença de duas línguas no interior da escola sem propiciar que cada uma assuma seu lugar de pertinência para os grupos que as utilizam, mantendo a hegemonia do português nos processos educacionais. (LODI, 2013, p.49)

Dessa forma, a concepção presente na Politica limita a transformação proposta para a educação de surdos apenas ao plano discursivo e restringe a inclusão à escola, impossibilitando uma ampliação desse conceito a todas as esferas sociais, conforme defendido pelo Decreto (LODI, 2013).

Neste contexto, o presente artigo tem por objetivo apresentar uma análise da literatura científica disponível sobre o processo de implementação da Libras como disciplina curricular obrigatória nos cursos de licenciaturas. Almeja-se reconhecer os contextos das pesquisas nos quais essa literatura foi gerada, sujeitos, métodos empregados na investigação, bem como suas contribuições para a ampliação do conhecimento neste campo específico.

\section{Nosso método de investigação}

Para o levantamento da literatura científica disponível sobre a implementação da Libras como disciplina curricular obrigatória nos cursos de licenciaturas optamos por analisar dissertaçôes e teses que tratassem desta temática. Deste modo, a coleta de dados ocorreu mediante acesso ao Banco de Teses da Coordenadoria de Aperfeiçoamento de Pessoal de Nível Superior (Capes), através do site http://capesdw.capes.gov.br/capesdw/, no qual há a possibilidade de acessar informaçôes sobre teses e dissertações defendidas junto aos programas de pós-graduação em todo o Brasil.

Delimitamos nossa busca em níveis e anos das bases: doutorado, mestrado e mestrado profissionalizante, com bases produzidas em quaisquer datas.

Como descritores dos assuntos a serem relacionados no processo de busca, optamos pelos termos "formação de professores", "ensino de Libras no ensino superior", "políticas educacionais inclusivas", "Libras nos cursos de licenciatura" e "implementação da disciplina de Libras", sempre combinando os termos entre si em grupos de três e/ou dois termos simultaneamente.

Procedemos então com a identificação das produções encontradas, partindo da leitura do título de cada trabalho apresentado nos resultados de buscas com as diferentes combinações entre os descritores.

A princípio, identificamos a existência de um número considerável de trabalhos. Após a leitura dos resumos, logo percebemos que muitos não correspondiam ao nosso foco de interesse, ou à combinação dos descritores, assim, muitos traba- 
lhos tratavam de alguma forma sobre a Libras, mas não tratavam da implementaçáo da disciplina de Libras nos cursos de licenciaturas. O que nos levou a selecionar apenas os trabalhos que correspondiam ao objeto de estudo, refinando nossa busca.

Ao identificarmos o trabalho como objeto de estudo, ou seja, cada tese e/ ou dissertação que tratasse da implementação da disciplina de Libras nos cursos de licenciaturas, acessamos e lemos novamente seus respectivos resumos e organizamos dados em um quadro, tais como nome dos autores, título do trabalho, instituição de origem e orientadores, conforme Quadro 1.

Podemos notar a ausência de teses de doutorado, o que pode denotar carência do acompanhamento do processo de implementação da disciplina de Libras nos cursos de licenciatura sob a perspectiva de uma pesquisa com o rigor e nível científico mais elaborado como é esperado de um trabalho de doutorado. Também não houve incidência de dissertaçóes na base "mestrado profissionalizante". Há que se considerar o quâo recente é a temática proposta.

Os descritores permitiram a seleção de sete dissertações de mestrado que apresentaram a discussão sobre a implementação da disciplina de Libras nos cursos de licenciaturas como tema principal ou tema correlato de pesquisa.

Foi possível o acesso a seis trabalhos completos através de mecanismos diversos de busca na internet, como sítios oficiais de universidades e seus programas de pós-graduaçáo, entre outros.

Uma vez constituído o corpus da pesquisa, procedemos à coleta dos dados que nos possibilitasse caracterizá-las, identificando sua temática central e/ou objetivos, local de realização, procedimentos e/ou instrumentos metodológicos e sujeitos de pesquisa. Para tanto, retomamos a leitura do resumo de cada dissertação em busca dessas informaçóes. As informaçóes foram transcritas e organizadas em arquivo digital de texto para melhor visualização.

Após isso, foram realizadas leituras na íntegra das seis dissertaçóes acessadas, buscando compreender o processo investigativo adotado pelos autores e maior aproximação com os aspectos trabalhados e expressos relacionados aos resultados e discussóes de cada um dos estudos.

\section{Resultados e discussões}

Partindo da ordem cronológica de defesa dos trabalhos, a primeira dissertação data do ano de 2008, ou seja, três anos depois da publicação do Decreto n. 5.626/2005.

Em estudo intitulado Os desafios da implementação do ensino de Libras no Ensino Superior, Pereira (2008) procura verificar o cumprimento da Lei n. 10.436 de acordo com o Decreto n. 5.626/2005 no que tange à implementação da disci- 
Quadro 1. Dissertaçôes selecionadas entre as cadastradas no Banco de Teses da Capes

1) Autor: Terezinha de Lourdes Pereira (2008)

Título: Os desafios da implementação do ensino de Libras no Ensino Superior

Programa de Pós-graduação (Ppg) - Instituição: PPG em Educação - Centro

Universitário Moura Lacerda de Ribeirão Preto, SP

Orientador: Profa. dra. Tárcia Regina da Silveira Dias

2) Autor: Cristina Costa de Moraes (2011)*

Título: A institucionalização da Libras nas universidades: representaçōes sociais de professores dos cursos de licenciatura sobre a inclusão de surdos

Programa de Pós-graduaçáo (Ppg) - Instituição: Mestrado em Educação da

Universidade Estácio de Sá, Rio de Janeiro

Orientador: Profa. dra. Rita de Cassia Pereira Lima

3) Autor: Elissandra Lourenço Perse (2011)

Título: Ementas de Libras nos espaços acadêmicos: que profissionais para qual inclusäo?

Programa de Pós-graduaçáo (Ppg) - Instituição: PPG em Letras (Linguística) da Universidade do Estado do Rio de Janeiro

Orientador: Profa. dra. Del Carmem Daher

4) Autor: Cleuza Kuhn (2011)

Título: Educação inclusiva: das açôes institucionais à formação inicial dos professores na UFPR

Programa de Pós-graduação (Ppg) - Instituição: PPG em Educação da Universidade Federal do Paraná

Orientador: Profa. dra. Laura Ceretta Moreira

5) Autor: Josiane Junia Facundo de Almeida (2012)

Título: Libras na formação de professores: percepções dos alunos e da professora

Programa de Pós-graduaçáo (Ppg) - Instituição: PPG em Educação da Universidade Estadual de Londrina

Orientador: Profa. dra. Célia Regina Vitaliano

6) Autor: Fernanda Cilene Moreira de Meira (2012)

Título: Atitude social e inclusão de alunos surdos: os impactos da obrigatoriedade da disciplina de Libras nos cursos de formação de educadores

Programa de Pós-graduaçáo (Ppg) - Instituiçáo: PPG em Distúrbios do Desenvolvimento da Universidade Presbiteriana Mackenzie, São Paulo

Orientador: Profa. dra. Beatriz Regina Pereira Saeta

7) Autor: Rúbem da Silva Soares (2013)

Título: Educação bilingue de surdos: desafios para a formação de professores

Programa de Pós-graduaçáo (Ppg) - Instituiçáa: PPG em Educação da Universidade de São Paulo (Faculdade de Educação)

Orientador: Profa. dra. Rosangela Gavioli Prieto

Fonte: Dados da pesquisa.

* Não foi possível o acesso à dissertação completa. 
plina de Libras como disciplina curricular obrigatória nos cursos de formação de professores e Fonoaudiologia.

O estudo foi realizado em oito IES da rede privada localizadas em oito municípios diferentes, quatro no interior do Estado de São Paulo e quatro no interior do Estado de Minas Gerais. As IES investigadas apresentaram um total de 10 cursos (6 de Pedagogia, 2 de Letras, 1 Normal Superior e 1 de Fonoaudiologia) alvo da implementação da disciplina.

A autora denomina sua pesquisa como um estudo de campo e descritivo, e seu instrumento de coleta como entrevista "semiestruturada in loco", atribuindo aos coordenadores de cursos das instituiçóes pesquisadas a responsabilidade pela implementação da disciplina de Libras nos cursos de graduação das mesmas.

Como resultado, Pereira (2008) destaca que das oito IES pesquisadas naquela época, três já haviam implementado a disciplina de Libras em seus cursos de graduação; três contemplavam a disciplina nas matrizes curriculares dos cursos, mas não haviam implementado de fato a disciplina; e as outras duas ainda não haviam iniciado o processo. A autora aponta também que nesse contexto, dos dez cursos pesquisados, apenas quatro já haviam implementado a disciplina efetivamente, enquanto cinco tentaram contemplar o ensino da Libras através de palestras ou inserindo-a dentro de outras disciplinas.

Outro aspecto que a autora destaca é que, das três IES que implementaram a disciplina de Libras, duas contavam com professores surdos e a terceira com professores ouvintes fluentes em Libras.

Como conclusão do estudo, os principais apontamentos de Pereira (2008) são que a falta de conhecimento acerca da legislação sobre a Libras e a educação de surdos por parte dos coordenadores de curso dificultava a implementação da disciplina de Libras; que as cargas horárias das disciplinas ofertadas eram insuficientes para o ensino da Libras em sua totalidade, apontando em suas discussóes a concordância com seus entrevistados sobre esse aspecto e; deu destaque para a "falta de apoio dos órgãos responsáveis em assessorar o Projeto Político-Pedagógico das instituiçóes particulares" (PEREIRA, 2008, p.79) para nortear a implementação da disciplina de Libras.

Vale destacarmos que nos parece ingênuo almejar ensinar uma língua em sua totalidade para alunos dos diversos cursos de licenciaturas no espaço de uma disciplina, tenha ela 30 ou mais horas. Esse não parece ser o propósito do Decreto n. 5.626/2005, ao nosso ver.

É preciso estar atento a essa questão, mas também é preciso considerar o papel da disciplina de Libras em cada curso em que é implementada diante dos pressupostos da educaçáo bilíngue para surdos. Uma ideia equivocada do papel dessa disciplina pode não somente impossibilitar o sucesso de sua implementaçáo, como forjar seu fracasso por falta de clareza de seus propósitos. 
A pesquisa de Pereira (2008) focaliza o início da implementação da disciplina de Libras e já levanta o debate da pertinência de professores ouvintes serem responsáveis por essa disciplina, mesmo que a legislação priorize a contratação de surdos para essa funçáo. Há que se considerar a baixa oferta de profissionais qualificados surdos na época de seu estudo.

Podemos perceber também no estudo supracitado aspectos de possível procrastinação da implementação da disciplina de Libras, na medida em que algumas IES procuram alternativas para atender a Lei, como sua previsão nos documentos oficiais da instituição, mas de concreto apenas a realização de palestras e cursos de extensão.

Perse (2011), em sua dissertação de mestrado, Ementas de Libras nos espaços acadêmicos: que profissionais para qual inclusāo?, se mostra interessada em verificar a implementação das disciplinas de Libras e Ensino de Língua Portuguesa como segunda língua (L2) para surdos nas grades curriculares das cinco universidades públicas do Estado do Rio de Janeiro, e na identificação dos discursos sobre a surdez, Libras e as concepçóes sobre ensino de línguas nesses espaços.

A autora realiza pesquisa exploratória que, segundo a mesma, se aproxima de pesquisa diagnóstica e estudo de caso, ressaltando a escassez de estudos anteriores sobre o tema. O corpus para sua pesquisa constituiu-se das ementas das disciplinas de Libras e Língua Portuguesa como segunda língua para surdos junto às referidas universidades, bem como o Decreto n. 5.626/2005, mais especificamente os artigos $3^{\circ}$ e $13^{\circ} .^{4}$

A autora demonstra por meio de seus resultados que das cinco universidades pesquisadas, quatro contemplaram o Decreto em relação à implementação da Libras nas licenciaturas, apenas uma implementou a disciplina de Língua Portuguesa como L2 para surdos no curso de Letras e nenhuma implementou esta última disciplina nos cursos de Pedagogia.

A autora discute o gênero "ementa" e os elementos que o documento deve conter, bem como os espaços que a disciplina de Libras ocupa nas universidades e seu vínculo com institutos e departamentos, além do perfil dos professores das disciplinas.

Perse (2011) conclui que o entendimento diferente sobre a implementação das exigências do Decreto por cada universidade faz com que se instituam distintos perfis de seus profissionais egressos. Além disso, conclui que há nesses espaços o predomínio de uma concepção de ensino de línguas baseada numa visão estruturalista de língua e na decodificação de vocábulos.

4 Os artigos $3^{\circ}$ e $13^{\circ}$ do Decreto n. 5.626/2005 tratam da implementação da disciplina de Libras na grade curricular dos cursos de formaçáo de professores e Fonoaudiologia e da implementação de disciplina de ensino de língua portuguesa na modalidade escrita para surdos nos cursos de Pedagogia e Letras com habilitação em língua portuguesa. 
O estudo de Perse (2011) contribui para evidenciar algumas questóes importantes sobre a implementação da disciplina de Libras a partir da ótica da área da linguística e seu respectivo referencial teórico, questionando a relevância das determinaçóes do Decreto n. 5.626/2005, partindo da impossibilidade de se ensinar uma língua no contexto de uma disciplina e, nesse âmbito, dificultar a consolidação da Libras enquanto língua nos espaços acadêmicos, questionando ainda a preocupação das instituiçóes em aparentemente apenas cumprir a legislação sem contemplar efetivamente as exigências de formação de professores para educação de surdos.

Reiteramos nossa postura sobre os propósitos de disciplinas de Libras nos cursos de formação de professores: que devem considerar os níveis de ensino e os pressupostos da educação bilíngue para surdos dispostos no Decreto n. 5.626/2005, conforme já citados neste artigo. Concordamos com a autora sobre os diferentes encaminhamentos na implementação da disciplina de Libras de acordo com os contextos em que estiver inserida, no entanto, é preciso considerarmos que, segundo o Decreto, todas as IES devem incluir a disciplina de Libras em seus cursos de licenciaturas; por outro lado, a forma como essa medida é efetivada é de responsabilidade e, ao mesmo tempo, direito das instituiçóes, prevista na Constituição Federal de 1988 (art. 207, caput): "As universidades gozam de autonomia didático-científica, administrativa e de gestão financeira e patrimonial, e obedecerão ao princípio de indissociabilidade entre ensino, pesquisa e extensão".

Desse modo, se acredita nos potenciais científicos e éticos da academia, locus de conhecimento e crítica, em medidas como contratação e mobilização dos profissionais capacitados para elaboração de disciplinas que respeitem as demandas e realidades em que estão situados.

Kuhn (2011) defende sua dissertação de mestrado, intitulada Educação inclusiva: das açôes institucionais à formação inicial dos professores na UFPR, apresentando como objetivo analisar a formação inicial de professores em três cursos de licenciatura da Universidade Federal do Paraná (UFPR), bem como açóes e iniciativas adotadas pela universidade com relação às Necessidades Educacionais Especiais (NEE) e verificar esses aspectos frente à educação inclusiva.

A autora realiza pesquisa qualitativa divida em duas fases. Na primeira, realiza pesquisa documental, definindo como corpus os projetos pedagógicos de quatorze cursos presenciais de licenciatura da UFPR, dos quais elegeu três que já estivessem adaptados à reforma curricular e apresentassem histórico de participação de alunos com NEE em seus programas, bem como os documentos oficiais em nível federal e estadual sobre educação inclusiva.

$\mathrm{Na}$ segunda fase realiza entrevista semiestruturada com os três coordenadores dos três cursos eleitos na primeira fase de pesquisa, bem como com nove professores, entre os quais havia os que já lecionaram disciplinas sobre educação especial ou políticas formativas e os que atuavam em áreas alheias ao tema da pesquisa. 
Kuhn (2011) analisa seus dados a partir da perspectiva da análise de conteúdo elegendo três principais categorias analíticas: formação inicial e continuada, açóes e iniciativas da UFPR, e educação inclusiva.

Com seus resultados, a autora concluiu que mesmo após reestruturação dos projetos pedagógicos dos cursos de licenciatura analisados, os mesmos demonstravam poucos avanços no que se refere à perspectiva inclusiva e constata que a disciplina de Libras foi incorporada de forma obrigatória em todos os cursos apenas com vistas a atender o Decreto n. 5.626/2005, e que em um dos cursos analisados, a disciplina de Fundamentos da Educação Especial teve sua carga horária duplicada.

Esse estudo corrobora com o protagonismo da disciplina de Libras no Decreto n. 5.626/2005 e reforça o papel desta lei na indução de iniciativas de atendimento aos direitos das pessoas surdas, sobretudo o direito à educação. Mais que isso, para além da educação de surdos, a medida inédita de implementação da disciplina de Libras nos cursos de formação de professores no ensino superior por força de lei torna-a protagonista também no que tange ao atendimento da inclusão escolar de alunos com deficiências de um modo geral. No entanto, mesmo instituições que pretendem pensar-se inclusivas, apenas implementam a disciplina de Libras por força de lei e não chegam a alterar de maneira significativa seus fazeres e modos de pensar.

A dissertação de mestrado de Almeida (2012), intitulada Libras na formação de professores: percepçóes dos alunos e da professora, apresenta como objetivo caracterizar a implementação da disciplina de Libras no curso de Pedagogia da Universidade Estadual de Londrina (UEL) e seus efeitos junto aos graduandos, bem como analisar as percepçóes da professora sobre a organização e objetivos da disciplina de Libras no currículo do curso de Pedagogia.

A autora considera seu estudo como pesquisa de abordagem quantitativa e qualitativa, optando pelo processo investigativo do estudo de caso intrínseco, considerando aproximaçóes com estudo de avaliação de um programa. Como coleta de dados foi realizada entrevista semiestruturada com a professora da disciplina de Libras, aplicação de questionário com 40 alunos que já haviam finalizado a disciplina de Libras e análise do programa da disciplina.

Sobre a análise do programa da disciplina, a autora aponta que os conteúdos e objetivos da disciplina focalizam os aspectos linguísticos e o desenvolvimento de atividades práticas pertinentes à Libras.

A autora discute os resultados coletados a partir do questionário e conclui que muitos alunos, mesmo depois de terem finalizado a disciplina de Libras, ainda se sentiam inseguros em receber alunos surdos em suas salas de aula. A autora acredita que essa insegurança seja generalizada em relaçáo à atuaçáo de forma ampla, nâo especificamente com alunos surdos, uma vez que esses estudantes ainda não tiveram experiência profissional em sala de aula. 
Quanto aos resultados da entrevista com a professora da disciplina de Libras, Almeida (2012) destaca que a professora surda concebe como o principal objetivo da disciplina sensibilizar os graduandos para o trabalho com alunos surdos por meio do conhecimento da cultura surda e da língua de sinais.

Em suas principais consideraçóes finais, a autora aponta para os problemas encontrados pela baixa carga horária da disciplina, alertando para que se explicitem: os objetivos da disciplina de modo a não se criar expectativas sobre o domínio da língua; a quantidade de alunos por turma; e a falta de um profissional tradutor/intérprete de língua de sinais para acompanhar a professora surda em todas as instâncias acadêmicas. A autora conclui que é preciso aprimorar as contribuiçóes que a disciplina de Libras pode oferecer à preparação de graduandos para a inclusão escolar de alunos surdos.

Assim como nos estudos anteriores aqui tratados, a pesquisa de Almeida (2012) nos chama a atenção para questionamentos acerca da carga horária das disciplinas de Libras pesquisadas. No entanto, a pesquisa de Almeida (2012) nos revela um cenário mais realista de implementação da disciplina de Libras, não partindo do pressuposto do ensino de uma língua em sua completude, mas definindo seus objetivos de acordo com o contexto de sua implementação, considerando como tarefa básica da disciplina ministrar noçóes básicas da Libras.

Também são relevantes os apontamentos do estudo sobre a insegurança dos alunos relacionada com sua inexperiência profissional e não por um fracasso da disciplina. Além disso, destaca-se que a presença de professor surdo contribui para a formação em Libras e experiências relativas à inclusão, mas não encerra os problemas da consolidação da disciplina de Libras. Sobre este último aspecto, o estudo aponta a necessidade de tradutor/intérprete de Libras em todas as instâncias acadêmicas, mas ao nosso ver, a presença de tal profissional se configura mais como direito do profissional surdo, de acordo com sua escolha. Neste contexto, a presença desse profissional em sala de aula talvez seja importante em um primeiro momento, como no início da disciplina para apresentaçóes e contextualização, mas com tendência a sair de cena e deixar a comunicação direta entre professor surdo e os alunos que estão em situação de aprendizagem dessa língua. Entendemos que a experiência dos estudantes ouvintes com o professor surdo pode ser menos proveitosa se ela for sempre mediada pela presença do intérprete de Libras.

Meira (2012), em sua dissertação de mestrado intitulada Atitude social e inclusão de alunos surdos: os impactos da obrigatoriedade da disciplina de Libras nos cursos de formação de educadores, tem como objetivo analisar a intervenção da disciplina de Libras sobre a atitude social explícita e implícita nos discentes dos cursos de Pedagogia e licenciaturas em relação à inclusão do aluno surdo.

A autora realiza pesquisa quantitativa e qualitativa, lançando mão de questionário de identificação de atitude social em relação à inclusão de alunos surdos e teste de 
associação implícita aplicados a 38 alunos dos cursos de formação de professores que frequentaram a disciplina de Libras em uma universidade da rede privada.

Para Meira (2012), os resultados do estudo revelam que houve variação significativa nas atitudes implícitas e explícitas dos alunos ao comparar os momentos pré e pós-passagem pela disciplina de Libras, o que para ela indica diminuição da preferência por alunos sem deficiência e maior disponibilidade em relação à inclusão de alunos surdos.

A autora conclui em seu estudo que disciplinas relacionadas à inclusão afetam positivamente a atitude social dos professores em processo de formação e apresentam-se como política pública eficiente na minimização das barreiras em relação à inclusão.

Esse estudo colabora com as discussões acerca da implementação da disciplina de Libras no tocante a aceitação dos alunos pela mesma. Além disso, evidencia as potencialidades da disciplina de Libras em gerar mudanças de paradigmas e como start para atitudes mais favoráveis à inclusão dos alunos surdos por parte dos futuros professores.

Assim como no estudo de Kuhn (2011), a pesquisa de Meira (2012) corrobora com a ideia de que as consequências da implementação da disciplina de Libras de forma obrigatória nos currículos dos cursos de formação de professores extrapolam o campo da educação de surdos, chamando a atenção dos espaços acadêmicos para a formação de profissionais que favoreçam a inclusão de pessoas com deficiências.

Soares (2013), em sua dissertação de mestrado intitulada Educação bilíngue de surdos: desafios para a formação de professores, busca discutir a formação em cursos de licenciatura em Pedagogia e Letras em IES tendo em vista as determinaçóes do Decreto n. 5.626/2005, com o objetivo de elencar quais são os principais desafios na formação inicial de professores para a educação básica, considerando que esses professores deverão atender alunos surdos no contexto da educaçáo bilíngue em que a língua portuguesa na modalidade escrita deve ocupar o espaço de L2.

O autor lança mão de pesquisa bibliográfica, destacando a escassez de trabalhos sobre a formação de professores no contexto apresentado, sobretudo focalizando língua portuguesa escrita como L2. Utiliza fontes do campo da surdez e Libras principalmente apoiado na abordagem socioantropológica, legislação pertinente ao campo da educação de surdos e educação especial e autores do campo da linguística aplicada que abordam os temas propostos.

Em seus resultados, Soares (2013) aponta para quatro desafios principais para a formação inicial dos professores que atuarão na educaçáo bilíngue para surdos: a formulação de diretrizes para a formação inicial com vistas a dotar o futuro professor de conhecimentos essenciais à sua boa prática docente com esse grupo de alunos; investimentos na construção de açóes que visem trabalhar as eventuais crenças que o professor pode ter sobre a (in)capacidade de aprendizagem desse aluno; reflexão sobre instrumentos dos quais o professor pode lançar 
mão para desenvolver uma metodologia e materiais que venham a ser eficientes no ensino de português-por-escrito para o aluno surdo; trabalho com esse futuro professor visando gerar conhecimentos linguísticos suficientes, que possibilitem a sua reflexão sobre o estatuto da Libras.

O autor conclui que, além da inserção da disciplina Libras, não foram localizadas produções que informem sobre açóes abrangentes que, eventualmente, as IES estejam promovendo para formar professores que atenderão aos alunos surdos na educação bilíngue. E, embora a legislação tenha previsto a criação de tais cursos, também não foram localizadas informaçóes de ações do MEC para que as IES cumpram essa previsão legal.

O estudo de Soares (2013) colabora com a discussão sobre a implementação da disciplina de Libras na medida em que procura apontar diretrizes que podem ser generalizadas para a implementação das disciplinas que visem formar professores para atender alunos surdos. E esse estudo, assim como o de que Kuhn (2011), apresenta a implementação da disciplina de Libras como única medida tomada pelas IES como medida de formação de professores com vistas à inclusão; e como Perse (2011), destaca a escassez de produçóes sobre o tema investigado.

\section{Tecendo considerações}

As contribuições desses estudos são ricas e diversas para a compreensão do processo de implementação da disciplina de Libras nas realidades pesquisadas.

Concordamos com Perse (2011) e Soares (2013) sobre a escassez de trabalhos publicados sobre este tema, se consideramos um processo de abrangência nacional tendo decorrido nove anos da promulgação do Decreto n. 5.626/2005.

Das questóes mais recorrentes, destacamos as discussóes acerca da carga horária das disciplinas de Libras, inegavelmente baixas, mas que aparentemente seguem os mesmos modelos de outras disciplinas de diversas áreas já existentes, se configurando conforme o curso, instituição, enfim, conforme o contexto de sua implementação.

Podemos notar que a disciplina de Libras para os cursos de licenciaturas se mostra mais afeita aos objetivos da inclusão escolar do que aos objetivos da educação bilíngue propriamente dito, apesar de seu valor de medida protagonista nas proposiçóes do Decreto n. 5.626/2005.

A implementação das disciplinas de Libras nos cursos de formação de professores está longe de resolver o problema da educação de surdos no Brasil, na verdade, mesmo em pleno desenvolvimento e se atendesse todas as expectativas de sua implementação, só resolveria parte da questão. Muitas outras medidas permanecem necessárias, no entanto, é inegável que os impactos dessa medida potencializam o interesse pelo debate acerca da inclusão escolar de alunos surdos e abre caminho para que mais medidas sejam tomadas no sentido da formação de recursos humanos para contemplar a inclusão escolar e social de alunos com deficiências. 


\section{Referências}

ALMEIDA, J. J. F. Libras na formação de professores: percepçóes de alunos e da professora. Dissertação (Mestrado em Educação). 2012. Universidade Estadual de Londrina, Centro de Educação, Comunicação e Artes, Programa de Pós-Graduação em Educação, 2012.

BRASIL. Constituição da República Federativa do Brasil. Brasília: Senado Federal, 1988.

BRASIL. Lei n. 10.436, de 24 de abril de 2002. Dispóe sobre a Língua Brasileira de Sinais e dá outras providências. Diário Oficial da Uniāo, Brasília, 25 abr. 2002a.

BRASIL. Decreto n. 5.626, de 22 de dezembro de 2005. Regulamenta a Lei n. 10.436, de 24 de abril de 2002, que dispóe sobre a Língua Brasileira de Sinais - Libras, e o art. 18 da Lei n. 10.098, de 19 de dezembro de 2000. Diário Oficial da União, Brasília, 23 dez. 2005.

KUHN , C. Educação inclusiva: das ações institucionais à formação inicial dos professores na UFPR. 2011. Dissertação (Mestrado em Educação). Programa de Pós-Graduação em Educação, Universidade Federal do Paraná, 2011.

LODI, A. C. B. Educação bilíngue para surdos e inclusão segundo a Política Nacional de Educação Especial e o Decreto n. 5.626/05. Educação e Pesquisa, São Paulo, v.39, n.1, p.49-63, jan.-mar. 2013.

MEIRA, F. C. M. Atitude social e inclusão de alunos surdos: os impactos da obrigatoriedade da disciplina de Libras nos cursos de formação de professores. 2012. Dissertação (Mestrado). Programa de Pós-Graduação em Distúrbios do Desenvolvimento, Universidade Presbiteriana Mackenzie, São Paulo, 2012.

MORAES, C. C. A institucionalização da Libras na universidade: representações sociais de professores dos cursos de licenciatura sobre a inclusão de surdos. 2011. Dissertação (Mestrado em Educação). Programa de Pós-Graduação em Educação, Universidade Estácio de Sá, Rio de Janeiro, 2011.

PEREIRA. T. L. Os desafios da implementação do ensino de Libras no Ensino Superior. Mestrado (Dissertação em Educação). Programa de Pós-Graduação em Educação, Centrou Universitário Moura Lacerda, Ribeirão Preto, 2008.

PERSE, E. L. Ementas de Libras nos espaços acadêmicos: que profissionais para qual inclusão? 2011. 202f. Dissertação (Mestrado em Linguística). Programa de Pós-Graduação em Linguística, Universidade do Estado do Rio de Janeiro, Instituto de Letras, Rio de Janeiro, 2011.

SOARES, R. S. Educação bilingue de surdos: desafios para a formação de professores. 2013.138f. Dissertação (Mestrado em Educação). Faculdade de Educação, Universidade de São Paulo, São Paulo, 2013. 


\section{Resumo}

\section{A implementação da disciplina de Libras no contexto dos cursos de licenciatura}

Com a promulgação do Decreto n. 5.625/2005 que regulamenta a Lei n. 10.436/2002 a qual reconhece a Língua Brasileira de Sinais (Libras) como meio legal de comunicação; determina que sejam garantidas formas para sua institucionalização e difusão; bem como implementação da Libras como disciplina curricular obrigatória nos cursos de magistério e Fonoaudiologia -, há um movimento para o reconhecimento da importância da Libras na educação dos surdos e busca-se levar os futuros professores a conhecer em alguma medida essa língua, procurando favorecer o atendimento educacional que prestarão aos alunos surdos. Diante disso, o presente artigo tem por objetivo apresentar uma análise da literatura científica disponível sobre o processo de implementação da Libras como disciplina curricular obrigatória nos cursos de licenciaturas. O corpus da pesquisa constituiu-se por teses e dissertaçóes sobre o referido tema. A coleta ocorreu mediante acesso ao Banco de Teses da Coordenação de Aperfeiçoamento de Pessoal de Nível Superior (Capes). Destacamos que a implementação das disciplinas de Libras nos cursos de licenciaturas está longe de resolver o problema da educaçáo de surdos no Brasil, mas que seus impactos potencializam o interesse pelo debate acerca da formaçáo de recursos humanos para contemplar a inclusáo escolar e social de alunos com deficiências.

Palavras-chave: Educação Especial. Disciplina de Libras. Formação de Professores. Educação Bilíngue Para Surdos.

\section{Abstract}

\section{The Implementation of the LIBRAS Discipline in the Context of Teaching Degree Courses}

Since the promulgation of a 2005 Decree which regulates a Law from 2002 there has been a movement to the recognition of the importance of LIBRAS in the education of the deaf and training of future teachers on this language seeking to favor the educational care that they will provide to deaf students. This law recognizes LIBRAS (Brazilian Sign Language) as a legal way of communication and determines the guarantee of its institutionalization and diffusion as well as the implementation of LIBRAS as a mandatory discipline in pedagogy and speech therapy courses. Based on this, the present article has the objective of presenting analysis of the available literature on the process of implementation of LIBRAs as mandatory discipline in teaching degree courses. The corpus of the research constitutes of thesis and dissertations on the given subject. The data gathering occurred through the database of CAPES (Higher Education Personnel Development Coordination). We highlight that the implementation of the LIBRAS disciplines in teaching degree courses is far from solving the problem of the education of the deaf in Brazil but its impacts enhances the interest in the debate of the human resources development to contemplate the educational and social inclusion of students with disabilities.

Keywords: Special Education. LIBRAS Discipline. Training of Teachers. Bilingual Education for the Deaf. 